\title{
A METHOD OF POLISHING FROZEN SECTIONS.
}

JOSEPH P. TUNIS.

In order to secure a series of clean cut sections of the adult human head for the demonstration of some of the anatomical relations of the accessory sinuses of the nose, the following method was found most satisfactory. It consists in polishing sawn sections, while still frozen hard, on a rapidly revolving wooden wheel wet with water and finely powdered pumice stone. A similar process is employed for beveling glass.

After employing this method, for more than two years, with a great variety of material, the results have been so uniformly successful as to warrant a detailed report. Connective tissue, muscles, bone and teeth polish with equal facility and smoothness. The resulting surfaces have the appearance of having been cut with a sharp knife.

Having secured a good adult head, it should be well frozen in a near-by refrigerating plant or during cold weather in the open. The sections, either frontal or horizontal, should then be sawn in the usual way by hand or by using the band-saw. The latter is much the quicker and easier proceeding. Whichever course is adopted, the section should be polished before it has a chance to thaw on a rapidly revolving wooden wheel (Fig. 1). This wheel must be run by power, horizontally, while a mixture of water and finely powdered pumice stone is playing constantly upon it. Heavy woolen gloves are useful and greasing the hands with vaseline, an advantage if many sections are to be polished at one time. Some little experience will be necessary to familiarize the operator with the proper use of the polishing machine. Plenty of pumice should be on hand, as one section may require a pound or more. It is best, therefore, to purchase the pumice in bulk, as the fine pumice supplied to dentists 
in small cylindrical boxes does not mix well with water, and is not to be compared with the commercial variety.

As soon as the section begins to thaw, it should be frozen again, as a soft specimen is quickly spoilt. This is due to the fact that the bones polish much more readily than the softer tissues. If it is desired to polish both sides of a specimen, it is usually necessary to freeze again after one side is finished. This refreezing, however, often detracts from the clean cut appearance of the finished surface, especially if the section is not immersed in water before it is frozen for the second time. If the section has a tendency to float above the surface in the freezing pan weighting with a strip of sheet lead is an advantage. A series of numbered pans make it easier to keep track of the sections.

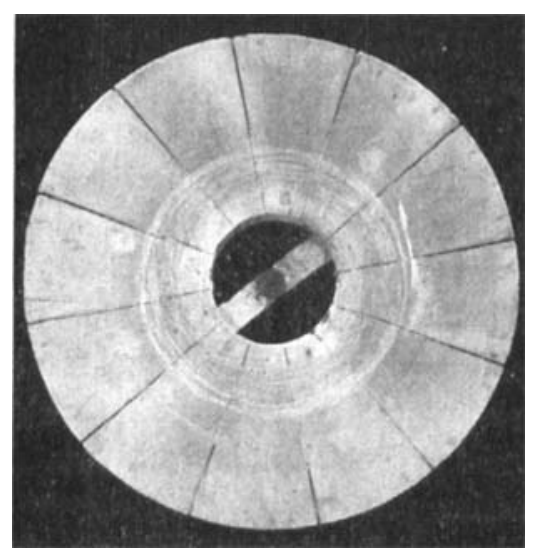

Fig. 1.-Wooden wheel for polishing frozen sections.

Fig. 2 shows photographs of the eighth section, made from the occiput forward, of a series from a woman's head (aged about seventy). They were made on a band saw and were each about half an inch thick. The anterior surface (Fig. 2, A) was not polished while the posterior surface (Fig. 2, B) was. A comparison of the surfaces illustrates the advantage of the method. Tracts in the spinal cord, or the distribution of the white and grey matter of the brain 
can be demonstrated in this way. In order to secure the best results with such material, however, the brain must be specially prepared.

To illustrate the anatomy of any particular part of the head, a good preliminary section having been secured, it would be an easy matter to photograph that surface, polish a little deeper, make a second photograph, polish again and so continue until a series of photographs, of the region desired, would have been made. The only objection to this plan would be that only the last polished surface would remain for preservation.

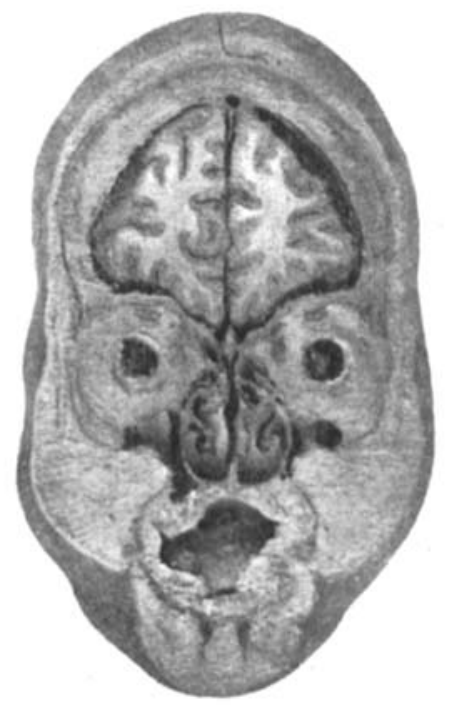

A.

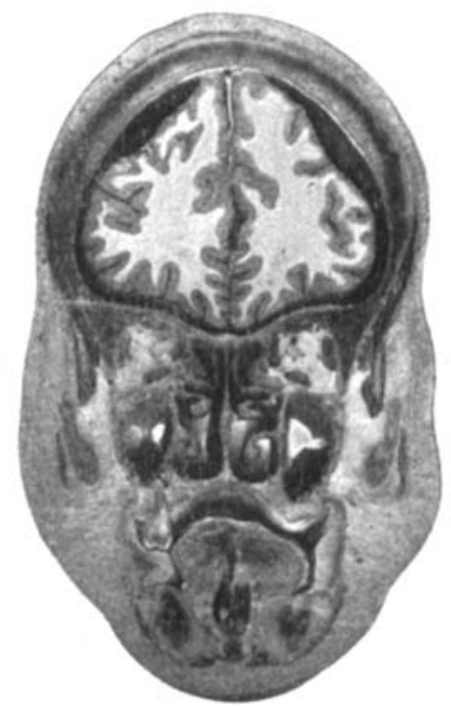

B.

FIg. 2.-A section of the human head. A, Anterior surface, not polished. B, Posterior surface, polished.

The most satisfactory plan to adopt in preserving a series of sections that I have found is to place them in a large jar horizontally, in a four per cent solution of formaline, with pieces of ordinary window glass between them. In this way any distortion of the section is prevented and they may be kept indefinitely for future reference. Kept in formaline, however, they will blanch more and more, so that the best photographs are obtained as soon as the spccimen has 
been polished. The wooden wheel shown in Fig. 1 was twenty-nine and a quarter inches in diameter, one and three quarters inches thick. A considerably smaller wheel would have answered the purpose just as well.

As far as I can determine from a careful search through the literature of this subject, no report has been published of any similar attempt to polish the frozen surfaces of sections. For the use of all the needed apparatus I am indebted to the Wistar Institute.

Received for publication, October 27, 1908.

\section{A SLIDEHOLDER FOR SERIAL WORK.}

BY

H. E. RADASCH.

From the Anatomical Laboratory of the Jefferson Medical College.

Although a number of slideholders have been described, nothing seemingly suitable for large 2 by 3 inch slides, used in serial embryologic work, has been suggested. The writer desires to present an apparatus that is not only light and cheap, but that can be readily constructed by any one. The holders are made of thin aluminium, this metal having proved satisfactory from all standpoints.

A strip about $1 / 75$ th of an inch in thickness and measuring $61 / 4$ by $23 / 4$ inches is utilized for the base and sides. Each end of this strip is then nicked $1 / 4^{\text {th }}$ inch deep and $1 / 8^{\text {th }}$ wide for ten slides, as shown in Fig. 1; it is then bent at aa, bb, and $a^{\prime} a^{\prime}$ and $b^{\prime} b^{\prime}$ to assume the shape of Fig. 2. The distance bb' should be $31 / 8$ th inches. Another piece of the metal 31/4th inches long and $1 / 2$ inch wide is then nicked in the same way, having a $1 / 4$ th inch nick at each end at which place the metal is to be used as a clamp (Fig. 3, beyond cd). This strip is then bent at right angles at $c c^{\prime}$, then at $c d$ and $c^{\prime} d^{\prime}$ 